\title{
Cell division cycle associated 1 as a novel prognostic biomarker and therapeutic target for oral cancer
}

\author{
PHUNG MANH THANG ${ }^{1,2,4}$, ATSUSHI TAKANO ${ }^{1,2}$, YOSHIHIRO YOSHITAKE $^{3}$, \\ MASANORI SHINOHARA ${ }^{3}$, YOSHINORI MURAKAMI ${ }^{4}$ and YATARO DAIGO $^{1,2}$ \\ ${ }^{1}$ Center for Antibody and Vaccine Therapy, Research Hospital, Institute of Medical Science, The University of Tokyo, Tokyo; \\ ${ }^{2}$ Department of Medical Oncology and Cancer Center, Shiga University of Medical Science, Otsu; ${ }^{3}$ Department of Oral and \\ Maxillofacial Surgery, Kumamoto University, Kumamoto; ${ }^{4}$ Division of Molecular Pathology, \\ Institute of Medical Science, The University of Tokyo, Tokyo, Japan
}

Received June 4, 2016; Accepted July 25, 2016

DOI: $10.3892 /$ ijo.2016.3649

\begin{abstract}
Oral cavity carcinoma (OCC) is one of the most common causes of cancer-related death worldwide and has poor clinical outcome after standard therapies. Therefore, new prognostic biomarkers and therapeutic targets for OCC are urgently needed. We selected cell division cycle associated 1 (CDCA1) as a candidate OCC biomarker. Immunohistochemical analysis confirmed that CDCA1 protein was expressed in 67 of 99 OCC tissues (67.7\%), but not in healthy oral epithelia. CDCA1 expression was significantly associated with poor prognosis in OCC patients $(\mathrm{P}=0.0244)$. Knockdown of $C D C A 1$ by siRNAs significantly increased apoptosis of tumor cells. These data suggest that CDCA1 represents a novel prognostic biomarker and therapeutic target for OCC.
\end{abstract}

\section{Introduction}

Oral cavity carcinoma (OCC) is the most common malignant cancer worldwide, with 28,030 new cases and 5,850 deaths per year in the United States (1). OCC prevalence is increasing for many reasons, including excessive alcohol consumption, excessive smoking, human papilloma virus infection and lack of hygiene (2). Smoking and alcohol consumption are the main contributors to the rising prevalence of OCC (3-6). The 5-year survival rate of OCC is $75-90 \%$ for stage I and $10-22 \%$ for stage IV $(7,8)$. Surgery followed by radiotherapy is the primary treatment for early and localized advanced OCC. However, local and regional recurrences are reported in $90 \%$ of cases after surgery and radiotherapy treatment (9). Adjuvant chemotherapy after surgery improved survival of OCC patients

Correspondence to: Dr Yataro Daigo, Center for Antibody and Vaccine Therapy, Research Hospital, Institute of Medical Science, The University of Tokyo, 4-6-1 Shirokanedai, Minato-ku, Tokyo 108-8639, Japan

E-mail: ydaigo@ims.u-tokyo.ac.jp; ydaigo@belle.shiga-med.ac.jp

Key words: cell division cycle associated 1, prognostic biomarker, therapeutic target, oral cavity carcinoma, oncoantigen by $16 \%(10)$. Despite recent developments in treatment, the overall survival of OCC has improved by just $5 \%$ in the last 20 years $(6,11)$. Therefore, treatments for OCC clearly need to be improved; more personalized therapies and novel molecular therapies with fewer adverse events may represent more effective approaches (12).

To isolate potential molecular targets for the diagnosis and/or treatment of OCC, we performed genome-wide gene expression analyses and tissue microarray analyses of various solid tumor tissues. We identified several oncoantigens involved in the development and/or progression of cancer (13-36). Cell division cycle associated 1 (CDCAI) mRNA was overexpressed in cancer tissues, including OCC, colorectal, lung cancer, cholangiocellular carcinoma and urological cancer (33-36). In addition, HLA-A0201-restricted epitope peptides from the CDCA1 protein induced peptidespecific cytotoxic T lymphocytes, implicating CDCA1 as a likely target for molecular targeted therapy and/or immunotherapy (36). CDCA1 is a component of the Ndc80 complex, which contains two subcomplexes: (KNTC2)-NUF2 (CDCA1) and SPC24-SPC25. The NCD80 complex is involved in chromosome segregation and the spindle checkpoint (37). The attachment of CDCA1 to the kinetochore outer plate generates microtubule-dependent forces for chromosomal movement and protein assembly at the kinetochore during the spindle checkpoint. $C D C A 1$ is expressed in human cancers, but its specific role in OCC growth/survival or the clinical significance of CDCA1 protein as a tissue biomarker for OCC has not been determined $(38,39)$.

In the present study, we report that CDCA1 plays an essential role in the malignant potential and survival of OCC, and represents a promising diagnostic and prognostic tissue biomarker. In addition, CDCA1 is a potential therapeutic target for new molecular targeted therapies for OCC.

\section{Materials and methods}

Cell lines and clinical samples. The following cell lines were used in this study: seven human OCC cell lines (FaDu, CAL-27, HSC2, HSC3, HSC4, Ca9-22 and SCC-9 cells); dysplasia of human oral keratinocyte (DOK) cells; and human oral 
Table I. The human OCC cell lines and oral mucosa keratinocyte.

\begin{tabular}{lll}
\hline Cell line & \multicolumn{1}{c}{ Histology } & \multicolumn{1}{c}{ Resource distributor } \\
\hline FaDu & Squamous cell carcinoma of pharynx & ATCC $^{\mathrm{a}}$ \\
SCC9 & Squamous cell carcinoma of tongue & ATCC $^{\mathrm{a}}$ \\
CAL-27 & Squamous cell carcinoma of tongue & ATCC $^{\mathrm{a}}$ \\
Ca9-22 & Gingival squamous cell carcinoma & RIKEN BRC $^{\mathrm{b}}$ \\
HSC2 & Squamous cell carcinoma of mouth & RIKEN BRC $^{\mathrm{b}}$ \\
HSC3 & Squamous cell carcinoma of tongue & RIKEN BRC $^{\mathrm{b}}$ \\
HSC4 & Squamous cell carcinoma of tongue & RIKEN BRC $^{\mathrm{b}}$ \\
DOK & Dysplastic oral keratinocyte & European Collection of Cell Cultures \\
HOMK & Human oral mucosa keratinocyte & Cell Research Corporation Pte Ltd
\end{tabular}

${ }^{\mathrm{a} A m e r i c a n}$ Type Culture Collection; ${ }^{\mathrm{b}}$ IKEN BioResource Center.

mucosa keratinocytes (HOMK). The histology and suppliers of all cancer cells are summarized in Table I. All cells (except HOMK cells) were grown in culture medium supplemented with $10 \%$ fetal bovine serum (FBS) and antibiotics and were maintained at $37^{\circ} \mathrm{C}$ in an atmosphere of humidified air. HOMK cells were grown in medium supplemented with epilife defined growth supplement. Eight OCC tissue samples purchased from Origene (Rockville, MD, USA) were used for real-time PCR experiments.

Ninety-nine formalin-fixed primary OCC tissues (42 female, 57 male patients; median age, 66 years; age range, 28-92 years) and adjacent healthy tissues were obtained from patients undergoing surgery at the Department of Oral and Maxillofacial Surgery, Kumamoto University School of Medicine. The clinical stage of these tumor samples was judged according to the Union for International Cancer Control TNM classification. This study and the use of all clinical materials were approved by individual institutional ethics committees.

Quantitative real-time PCR. Total RNA was isolated from cultured cells and OCC tissues using Maxwell 16 LEV simplyRNA tissue kit (Promega Corp., Madison, WI, USA). Complementary DNA was synthesized using ReverTra Ace qPCR RT kit (Toyobo, Co., Ltd., Osaka, Japan). mRNAs were quantified by real-time PCR using TaqMan Universal Master Mix II and TaqMan assays on a StepOnePlus thermocycler (Applied Biosystems) according to the manufacturer's instructions. Each experiment was done in triplicate. ACTB (Hs01060665_g1) was used as an internal control and $C D C A 1$ (Hs00230097_m1) primers were used (Applied Biosystems, Foster City, CA, USA).

Western blotting. Cells were lysed in RIPA lysis buffer with protease inhibitors (Thermo Fisher Scientific, Waltham, MA, USA). Proteins separated by SDS-PAGE were transferred onto PVDF membranes (Trans-Blot Turbo Transfer Pack; Bio-Rad Laboratories, Hercules, CA, USA). After blocking with Block Ace solution (DS Pharma Biomedical, Co., Ltd., Osaka, Japan), membranes were incubated with anti-CDCA1 primary antibody (Abcam) for $1 \mathrm{~h}$. Immunoreactive proteins were incubated with horseradish peroxidase (HRP)-conjugated secondary antibodies (GE Healthcare Life Sciences, Chalfont,
$\mathrm{UK}$ ) for $1 \mathrm{~h}$ at room temperature. Protein bands were visualized by enhanced chemiluminescence using an ImageQuant LAS 4000 mini system (GE Healthcare Biosciences).

Immunocytochemical analysis. Cultured cells were washed twice with PBS(-), fixed in 4\% paraformaldehyde solution for $10 \mathrm{~min}$ at $37^{\circ} \mathrm{C}$, and permeabilized in PBS(-) containing $0.1 \%$ Triton X-100 for $3 \mathrm{~min}$. Non-specific binding sites were blocked with blocking solution (CAS Block; Invitrogen, Carlsbad, CA, USA) for $10 \mathrm{~min}$ at room temperature before incubating with human CDCA1 antibody solution for $1 \mathrm{~h}$ at room temperature. Alexa Fluor 488-conjugated goat anti-rabbit secondary antibody (Molecular Probes, Eugene, OR, USA) was added to detect endogenous CDCA1. Nuclei were stained with 4',6-diamidino-2-phenylindole (DAPI; Vector Laboratories, Burlingame, CA, USA). CDCA1 antibody staining was visualized with a fluorescence microscope (BZ-X710; Keyence, Osaka, Japan).

Immunohistochemistry and tissue microarray analysis. Tumor tissue microarrays were constructed using 99 formalin-fixed primary OCC tissues, which were removed during curative surgery without neoadjuvant chemotherapy. Tumor tissue microarrays were constructed according to the previously published procedures (13). To measure CDCA1 protein expression in paraffin-embedded OCC samples, we performed immunohistochemistry using a rabbit anti-CDCA1 antibody and the EnVision HRP kit (DakoCytomation A/S, Glostrup, Denmark). For antigen retrieval, slides were boiled in retrieval solution (DakoCytomation). A rabbit polyclonal anti-CDCA1 antibody was added to each slide after blocking endogenous peroxidase activity and unspecific binding sites. After primary antibody incubation, sections were incubated with an HRP-labeled anti-rabbit IgG secondary antibody (DakoCytomation). Substrate-chromogen was added to visualize labeled proteins and the specimens were counterstained with hematoxylin. The intensity of staining within each tumor tissue core was mostly homogeneous, therefore, the intensity of CDCA1 staining was semi-quantitatively evaluated by two independent investigators without prior knowledge of the clinicopathological data. Expression was recorded as absent, weak or strong. 

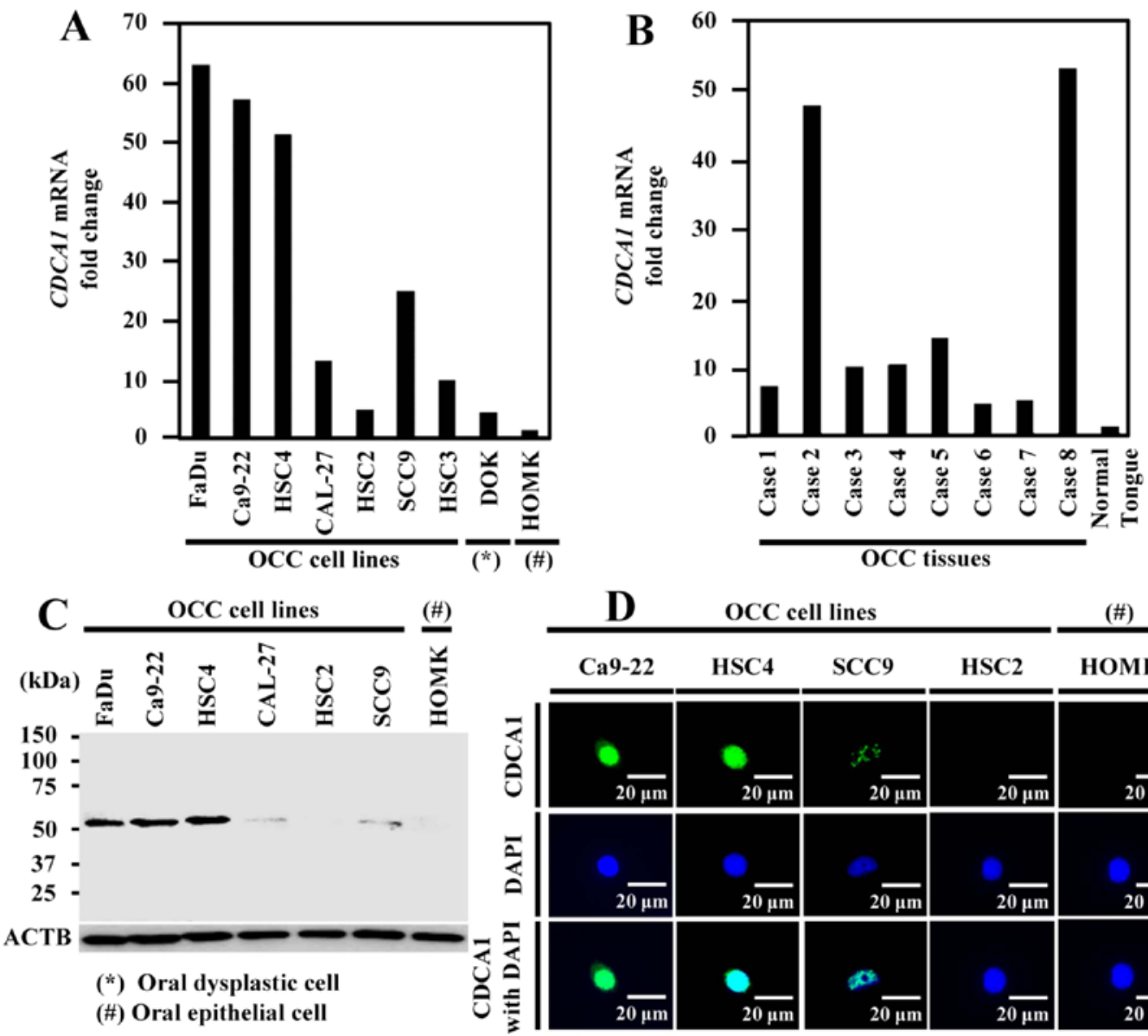

OCC cell lines

(\#)
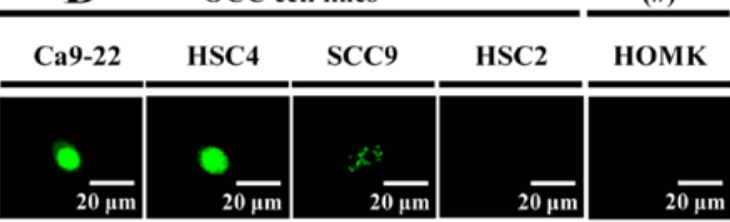

\#) Oral epithelial cell

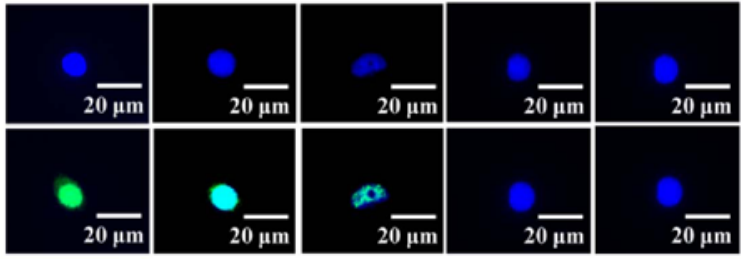

Figure 1. Expression of CDCA1 in OCC cells and OCC tissues. (A) Expression of CDCA1 in OCC cell lines. (B) Expression of CDCA1 in OCC tissues. (C) Expression of CDCA1 protein in OCC cells. (D) Subcellular localization of endogenous CDCA1 protein in HSC4, Ca9-22, SCC9, HSC2 and HOMK cells. Cells were stained with a rabbit polyclonal anti-CDCA1 antibody (green) and DAPI (blue).

Statistical analysis. We used contingency tables to correlate clinicopathological variables, (e.g., gender, age, region and pathological TNM stage), with CDCA1 protein expression levels determined by tissue microarray analysis. Survival curves were generated on the basis of the date of surgery or diagnosis to the time of death, or to the last follow-up observation. Kaplan-Meier curves were calculated for each relevant variable and for CDCA1 expression in oral tumors. Differences in survival times among patient subgroups were analyzed using the log-rank test. Univariate and multivariate analyses were performed with the Cox proportional hazard regression model to determine associations between clinicopathological variables and cancer-related mortality.

RNA interference assay. We transfected siRNAs (SigmaAldrich, St. Louis, MO, USA) into HSC4 and Ca9-22 cells, using Lipofectamine 2000 reagent (Invitrogen). The target sequences of the synthetic oligonucleotides for RNA interference were as follows: control 1 (luciferase: LUC) 5'-CGUACG CGGAAUACUUCGATT-3'; control 2 (EGFP) 5'-GAAGCAG CACGACUUCUUCTT-3'; siRNA-CDCA1-\#1, 5'-AAGAUG CUGCUGAAAGGGAGATT-3'; siRNA-CDCA1-\#2, 5'-GAA GUCAUGUUCCACAUUTT-3'. Five days after transfection, cell proliferation was evaluated by 3-(4,5-dimethylthiazol2-yl)-2,5-diphenyltetrazolium bromide (MTT) (Dojindo Molecular Technologies) and colony formation assays.
Flow cytometry. The cell cycle of OCC cells was analyzed using a Cycletest Plus DNA reagent kit (BD Biosciences, San Jose, CA, USA). Ca9-22 and HSC4 cells were transfected with si-CDCA1 or si-LUC. Seventy-two hours after siRNA transfection, $5 \times 10^{5}$ cells $/ \mathrm{ml}$ were collected for measuring DNA ploidy. Cell cycle analysis was performed within $3 \mathrm{~h}$ using a BD FACSVerse flow cytometer. The DNA content of cells selected from at least 20,000 ungated cells was measured.

Live cell imaging. HSC4 cells were seeded into 35-mm glass dishes in RPMI containing 10\% FBS. To investigate apoptosis $48 \mathrm{~h}$ after transfecting CDCA1 siRNA or control siRNA into HSC4 cells, we performed time-lapse imaging to detect the apoptotic cells using EVOS FL Auto cell imaging system (Life Technologies, Carlsbad, CA, USA). We captured images every $20 \mathrm{~min}$ for up to $96 \mathrm{~h}$.

\section{Results}

Expression of CDCA1 in OCC cells and tissues. CDCA1 mRNA was upregulated in six of the seven OCC cell lines, but expression was hardly detectable in healthy oral epithelial cells by real-time PCR (Fig. 1A). We confirmed increased $C D C A 1$ expression in all eight OCC tissues by real-time PCR and very low expression in healthy tongue tissue (Fig. 1B). In addition, CDCA1 protein was strongly expressed in five 


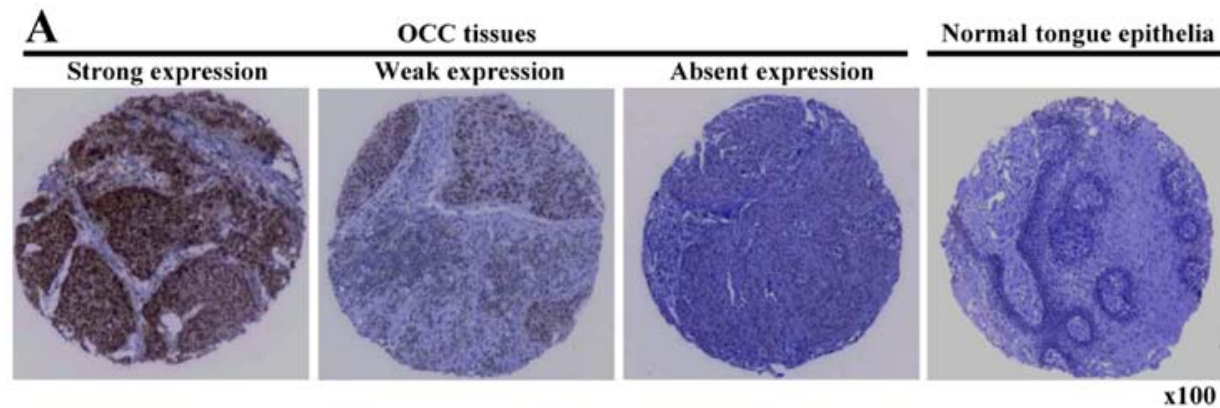

B

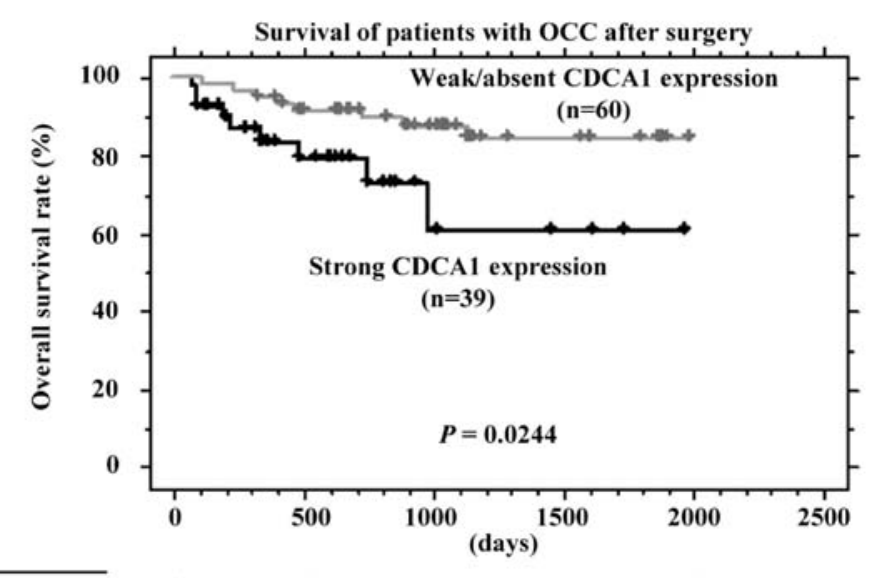

$\begin{array}{rllcccr}\text { Weak/absent CDCA1 expression } & 60 & 50 & 37 & 24 & 19 \\ \text { Strong CDCA1 expression } & 39 & 18 & 5 & 3 & 1\end{array}$

Figure 2. Association of CDCA1 expression with poor prognosis for OCC patients. (A) Immunohistochemical staining of CDCA1 protein in OCC tissues. Representative examples for strong, weak and absent CDCA1 expression in OCC tissues and healthy tongue epithelia (original magnification, x100).

(B) Kaplan-Meier analysis of survival in patients with OCC according to CDCA1 expression.

Table II. Association of CDCA1 protein expression in OCC tissues with the patient characteristics ( $\mathrm{n}=99)$.

\begin{tabular}{|c|c|c|c|c|c|}
\hline \multirow[b]{2}{*}{ Parameters } & \multirow[b]{2}{*}{ Total (99) } & \multicolumn{3}{|c|}{ CDCA1 protein } & \multirow{2}{*}{$\begin{array}{c}\text { P-value strong } \\
\text { positive vs. } \\
\text { weak/absent }\end{array}$} \\
\hline & & Strong expression (39) & Weak expression (28) & Absent expression (32) & \\
\hline \multicolumn{6}{|l|}{ Gender } \\
\hline Male & 57 & 22 & 18 & 17 & $>0.9999$ \\
\hline Female & 42 & 17 & 10 & 15 & \\
\hline \multicolumn{6}{|l|}{ Age (years) } \\
\hline$<65$ & 40 & 11 & 13 & 16 & $0.0063^{\mathrm{a}}$ \\
\hline$\geq 65$ & 59 & 28 & 15 & 16 & \\
\hline \multicolumn{6}{|l|}{ Region } \\
\hline Tongue & 50 & 18 & 21 & 11 & 0.5406 \\
\hline Others $^{\mathrm{b}}$ & 49 & 21 & 7 & 21 & \\
\hline \multicolumn{6}{|l|}{ pT factor } \\
\hline $\mathrm{T} 1+\mathrm{T} 2$ & 79 & 26 & 27 & 26 & $0.0112^{\mathrm{a}}$ \\
\hline $\mathrm{T} 3+\mathrm{T} 4$ & 20 & 13 & 1 & 6 & \\
\hline \multicolumn{6}{|l|}{$\mathrm{pN}$ factor } \\
\hline N0 & 82 & 28 & 25 & 29 & $0.0282^{\mathrm{a}}$ \\
\hline $\mathrm{N} 1+\mathrm{N} 2$ & 17 & 11 & 3 & 3 & \\
\hline
\end{tabular}

${ }^{\mathrm{a}} \mathrm{P}<0.05$ (Fisher's exact test). ${ }^{\mathrm{b}}$ Gingiva, Buccal mucosa and others.

out of six OCC cell lines using western blotting (Fig. 1C). Furthermore, immunocytochemical staining showed that CDCA1 protein was mainly located in nucleus of Ca9-22,
HSC4 and SCC9 cells, but no expression was detected in HSC2 and human oral mucosa keratinocytes (HOMK) cells (Fig. 1D). 
Table III. Cox's proportional hazards model analysis of prognostic factors in patients with OCC.

\begin{tabular}{|c|c|c|c|c|}
\hline Variables & Hazards ratio & $95 \% \mathrm{CI}$ & Unfavorable/favorable & P-value \\
\hline \multicolumn{5}{|l|}{ Univariate analysis } \\
\hline CDCA1 expression & 2.939 & $1.103-7.830$ & Strong vs. weak/absent & $0.0310^{\mathrm{b}}$ \\
\hline Age (years) & 2.812 & $0.914-8.648$ & $\geq 65 /<65$ & 0.0713 \\
\hline Gender & 1.667 & $0.643-4.324$ & Male/female & 0.2935 \\
\hline Region & 1.607 & $0.61-4.235$ & Tongue/others ${ }^{\mathrm{a}}$ & 0.3372 \\
\hline T-factor & 3.718 & $1.408-9.821$ & $\mathrm{~T} 3+\mathrm{T} 4 / \mathrm{T} 1+\mathrm{T} 2$ & $0.0080^{\mathrm{b}}$ \\
\hline N-factor & 2.902 & $1.012-8.321$ & $\mathrm{~N} 1+\mathrm{N} 2 / \mathrm{N} 0$ & $0.0474^{\mathrm{b}}$ \\
\hline \multicolumn{5}{|l|}{ Multivariate analysis } \\
\hline CDCA1 expression & 2.388 & $0.840-6.790$ & Strong vs. weak/absent & 0.1025 \\
\hline T-factor & 2.862 & $0.910-9.001$ & $\mathrm{~T} 3+\mathrm{T} 4 / \mathrm{T} 1+\mathrm{T} 2$ & 0.072 \\
\hline $\mathrm{N}$-factor & 1.283 & $0.359-4.583$ & $\mathrm{~N} 1+\mathrm{N} 2 / \mathrm{N} 0$ & 0.7013 \\
\hline
\end{tabular}

${ }^{\mathrm{a}}$ Gingiva, Buccal mucosa and others; ${ }^{\mathrm{b}} \mathrm{P}<0.05$.
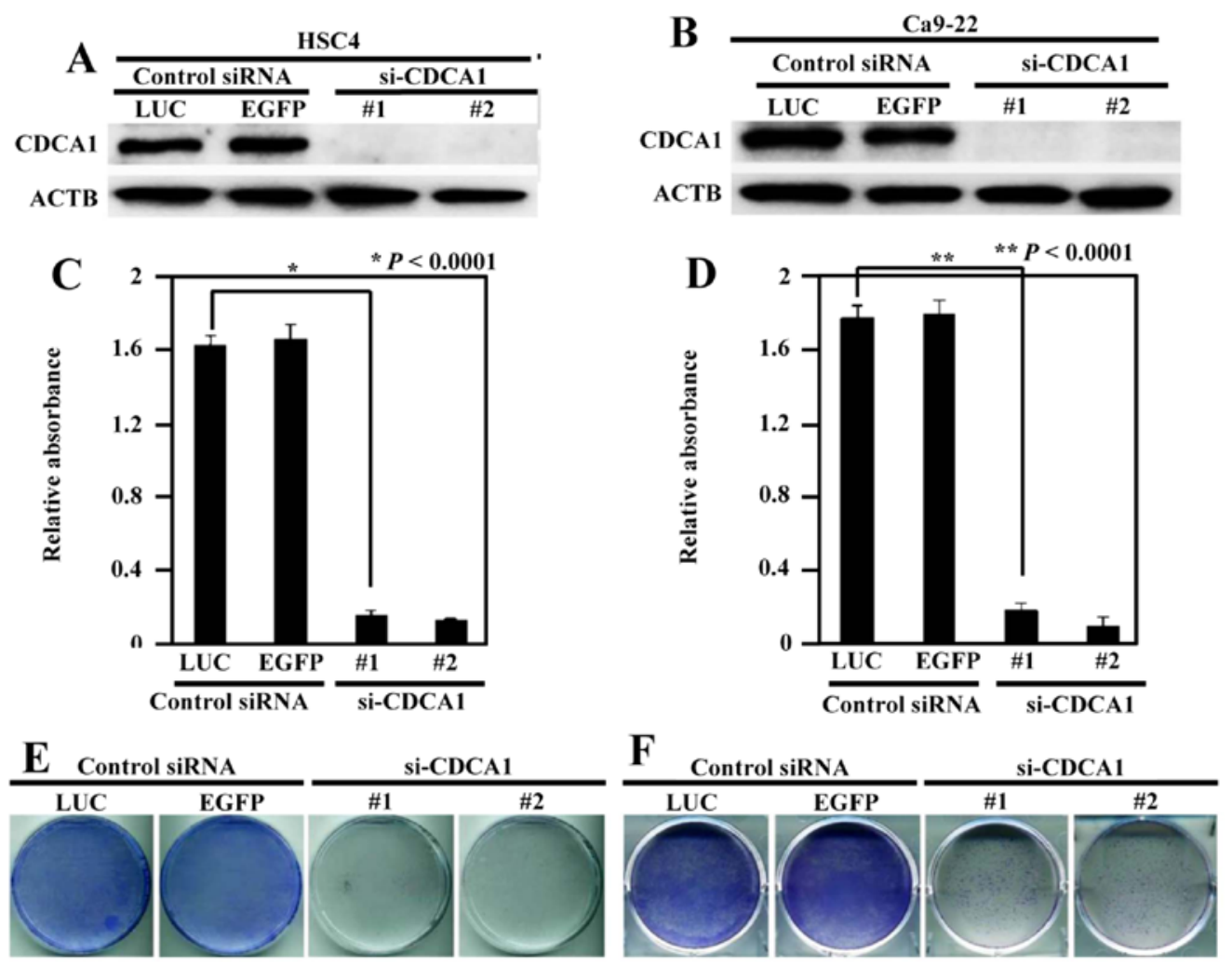

Figure 3. Inhibition of OCC cell growth by CDCA1 knockdown. (A and B) Expression of CDCA1 protein in HSC4 and Ca9-22 cells treated with CDCA1 siRNA or control siRNAs. (C and D) MTT assay of HSC4 and Ca9-22 cells transfected with CDCA1 siRNA or control siRNA. All assays were performed in triplicate. (E and F) Inhibition of HSC4 and $\mathrm{Ca} 9-22$ cell growth after CDCA1 knockdown using colony formation assay.

Association of CDCAl expression with OCC prognosis. Immunohistochemical analysis using tissue microarrays of 99 OCC samples demonstrated that CDCA1 staining was mainly in the cell nucleus and cytoplasm of cancer cells. Strong CDCA1 staining was observed in 39 OCC tissues (39.4\%), weak staining in 28 tissues (28.3\%) and absent staining in 32 cases (32.3\%). In contrast, the adjacent healthy tongue epithelial tissues were not stained (Fig. 2A). Next, we assessed the association of CDCA1 protein expression with the clinical parameters. Age factor (higher in $\geq 65$ years;
$\mathrm{P}=0.0063$ by Fisher's exact test), pT factor (higher in T3-T4; $\mathrm{P}=0.0112$ by Fisher's exact test), and $\mathrm{pN}$ factor (higher in $\mathrm{N} 1$ and $\mathrm{N} 2 ; \mathrm{P}=0.0282$ by Fisher's exact test) were significantly related to strong CDCA1 expression (Table II). Furthermore, strong CDCA1 expression was also significantly correlated with shorter survival compared with weak/absent CDCA1 expression ( $\mathrm{P}=0.0244$ by $\log$-rank test; Fig. 2B). We also performed univariate analysis to investigate the correlation between patient prognosis and other factors, including age ( $<65$ vs. $\geq 65$ years), gender (female vs. male), region (tongue 

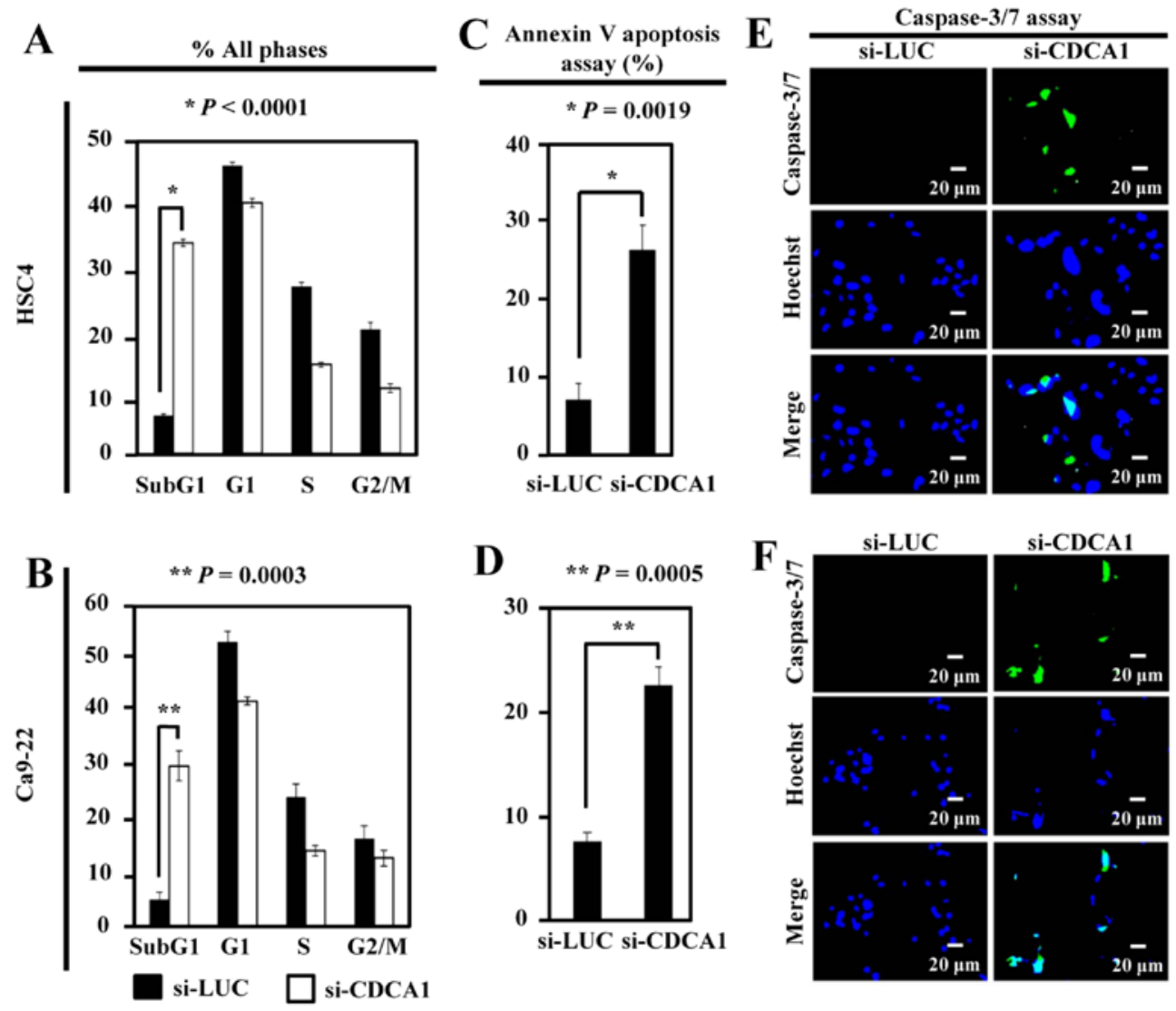

Figure 4. Induction of apoptosis by CDCA1 knockdown. (A and B) Percentage of cells at each phase using flow cytometric analysis of HSC4 and Ca9-22 cells after CDCA1 knockdown. (C and D) Percentage of apoptotic HSC4 and Ca9-22 cells after CDCA1 knockdown. (E and F) Detection of apoptotic HSC4 and Ca9-22 cells after CDCA1 knockdown by siRNA (apoptotic cells shown in green).

vs. other), $\mathrm{pT}$ classification (T1+T2 vs. T3+T4), $\mathrm{pN}$ classification (N0 vs. N1+N2) and CDCA1 expression status (strong vs. weak/absent). Among these parameters, strong CDCA1 expression $(\mathrm{P}=0.0310)$, advanced $\mathrm{pT}$ stage $(\mathrm{P}=0.0080)$ and advanced $\mathrm{pN}$ stage $(\mathrm{P}=0.0474)$ were significantly associated with poor prognosis (Table III).

Inhibition of the growth of OCC cells by knockdown of CDCA1 expression. To assess whether upregulation of CDCA1 played a significant role in the growth of OCC cells, we transfected CDCA1 siRNAs (si-CDCA1-\#1 and si-CDCA1-\#2) and control siRNAs (si-LUC and si-EGFP) into HSC4 and Ca9-22 cells. CDCA1 protein expression was reduced by siRNA-mediated knockdown (Fig. 3A and B). Suppression of CDCA1 protein expression significantly inhibited cell viability in HSC4 and Ca9-22 cells compared with controls $(\mathrm{P}<0.0001$ in both cell types) (Fig. 3C and D). In addition, colony formation assays demonstrated that reduced CDCA1 expression decreased the growth of HSC4 and Ca9-22 cells compared with controls (Fig. 3E and F).

To analyze the effects of CDCA1 on the cell cycle, flow cytometric analysis of HSC4 and Ca9-22 cells was performed $72 \mathrm{~h}$ after siRNA transfection. The proportion of cells in the sub-G1 phase was significantly higher in si-CDCA1transfected HSC4 and Ca9-22 cells than in controls $(\mathrm{P}<0.0001$ and $\mathrm{P}=0.0003$, respectively) (Fig. $4 \mathrm{~A}$ and $\mathrm{B}$ ). The number of apoptotic HSC4 and Ca9-22 cells was significantly higher after siRNA-mediated CDCA1 knockdown than in control cells
( $\mathrm{P}=0.0019$ and $\mathrm{P}=0.0005$, respectively) (Fig. 4C and $\mathrm{D})$. In addition, the caspase-3/-7 green assay demonstrated increased activation of caspase-3/-7 in OCC cells transfected with si-CDCA1 compared with control siRNAs (Fig. 4E and F).

To further clarify the effect of CDCA1 knockdown on cellular morphology and cell cycle, we performed live cell imaging of HSC4 cells transfected with CDCA1 siRNA using time-lapse microscopy. Dynamic HSC4 cell growth and survival were observed up to $96 \mathrm{~h}$ after siRNA transfection. Mitotic cells were observed $69 \mathrm{~h}$ after control-siRNA (si-LUC) transfection in HSC4 cells (white arrow). Daughter cells transfected with si-CDCA1 died (black arrow) after cell division, whereas cells transfected with control siRNAs survived (Fig. 5A). In addition, apoptosis-related proteins, including Bad, Bax, cleaved caspase-3, TRAIL R2/DR5 and cyclindependent kinase inhibitor 1A (CDKN1A) were enhanced in cells transfected with si-CDCA1 compared with control siRNAs (Fig. 5B and C).

\section{Discussion}

Molecular targeted therapies for OCC are currently being developed. They may provide better efficacy with fewer side-effects by specifically targeting cancer-related mechanisms. Molecular targeted drugs such as cetuximab (Erbitux) have now been approved by the Food and Drug Administration as an initial treatment of late-stage OCC in combination with chemotherapy. Current anticancer agents can prolong the 

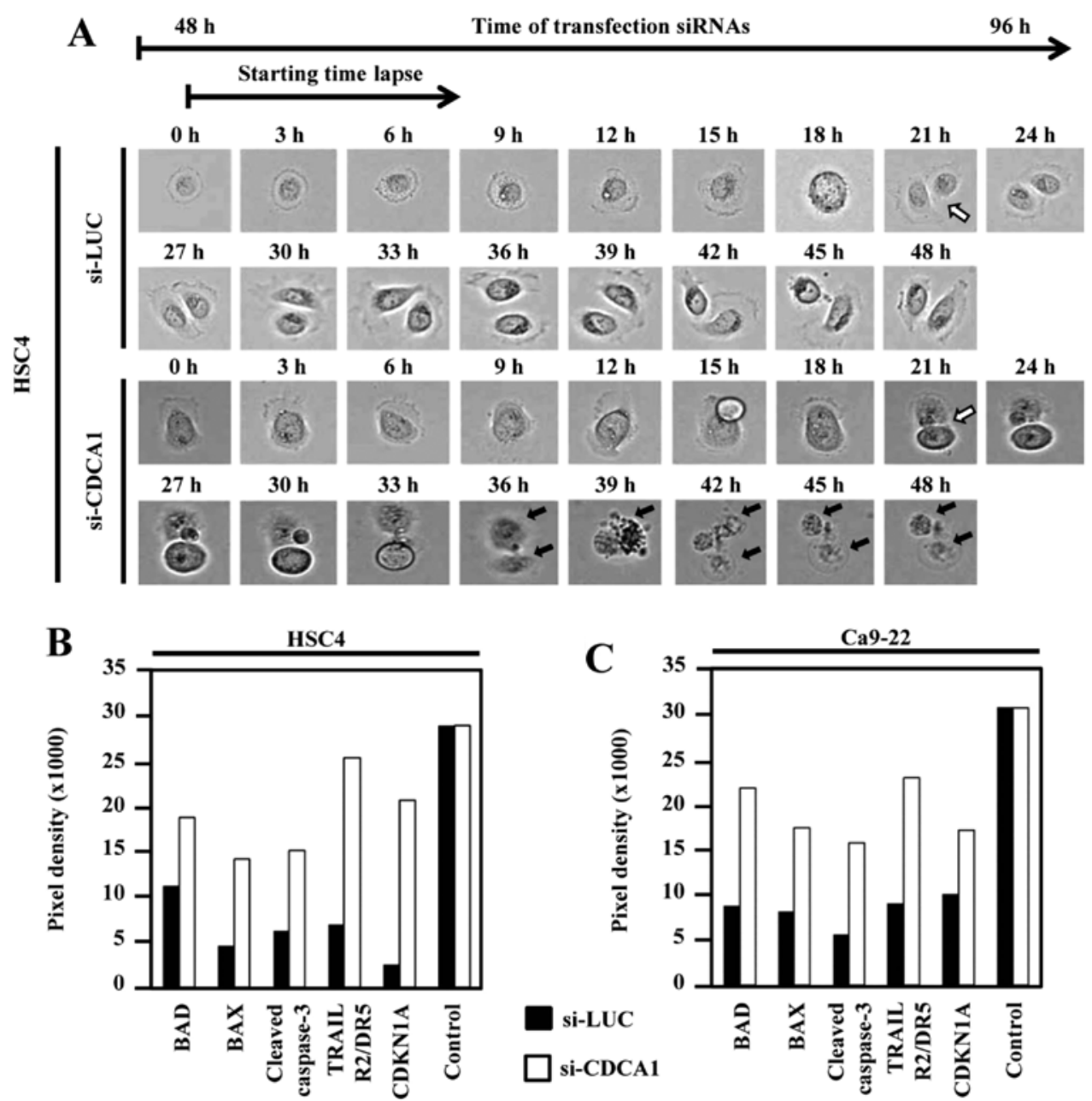

Figure 5. Dysfunctional mitotic daughter cells after CDCA1 knockdown. (A) Detection of mitotic daughter cells (white arrow) and apoptotic cells (black arrow) after CDCA1 knockdown by live cell imaging. (B and C) Screening cell cycle-related proteins and apoptosis-related proteins after CDCA1 knockdown in HSC4 and Ca9-22 cells.

overall survival of OCC patients, but they have limited efficacy and induce drug resistance. Therefore, new therapeutic target drugs for OCC are essential for improving the clinical outcome for patients.

In the present study, CDCA1 was overexpressed in OCC tissues and CDCA1 overexpression was significantly associated with poor prognosis. Furthermore, suppressing CDCA1 reduced OCC cell growth and promoted apoptosis. cBioportal for Cancer Genomics database (http://www.cbioportal.org/) revealed that $C D C A 1$ upregulation correlated significantly with poorer prognosis for head and neck cancer, thus, independently supported a prognostic potential of CDCA1 as a biomarker for OCC. To examine mechanism of CDCA1 activation in OCC, we collected comparative genome hybridization and genome sequencing data for CDCAl (http://cancer.sanger. ac.uk/cosmic/gene/). Missense mutations in $C D C A 1$ were detected in $0.78 \%$ of OCC tissues (2/255 cases), but no CDCA1 gene amplification or translocation was reported. Therefore, CDCA1 overexpression could be involved in an important epigenetic mechanism contributing to OCC.

CDCA1 is a highly conserved component of a nuclear division cycle complex and is categorized as an oncoantigen. We showed that suppression of CDCA1 significantly inhibited OCC cell growth and induced apoptosis in OCC cells, but the specific mechanisms remain unclear. According to our findings and previous studies, possible mechanisms exist for CDCA1-mediated regulation of OCC growth and survival: i) stable spindle microtubule-kinetochore attachment in mitotic prophase of highly proliferative cancer cells; ii) regulation of apoptosis pathways. CDCA1 protein belongs to the NDC80 complex, which contains CDCA1, HEC1, SPC24 and SPC25. CDCA1-HEC1 heterodimers interact with the plus ends of spindle microtubules and SPC24-SPC25 heterodimers anchor the complex into the kinetochore (40). CDCA1 plays a pivotal role in stable spindle microtubule-kinetochore attachment and stable microtubule localization of centromere-associated protein E (CENP-E) (41). Decreased CDCA1 expression inhibited kinetochore attachment to spindle microtubules, resulting in aberrant chromosome segregation, prolonged mitotic blockade and cell death (42-45). In the early phase of mitosis, after kinetochore attachment to spindle microtubules, this complex is stable and has a half-life of several minutes, which is essential for the next phase of mitosis. However, the complex is unstable and has a half-life of approximately $10 \mathrm{sec}$ when binding of the kinetochore to microtubules is impaired. This leads to abnormal cell division, resulting in dysfunctional daughter cells that eventually die. In agreement with previous findings, $C D C A 1$ knockdown in OCC cells resulted 
in impaired growth and apoptosis in cells. Downregulation of CDCA1 increased the expression of apoptosis-related proteins in OCC cells, including Bad, Bax, cleaved caspase-3 and TRAIL R2/DR5. The data suggested the dysregulation of appropriate cell division and subsequent induction of apoptosis of OCC cells through various mechanisms such as mitochondrial-dependent and caspase-dependent pathways.

In summary, CDCA1 is likely to play a significant role in OCC carcinogenesis. Importantly, CDCA1 is associated with growth and survival of OCC cells. Since CDCA1 was not expressed in healthy tissues, apart from the testis (33), it could be a highly specific cancer biomarker. In addition, targeting CDCA1 will lead to the development of new type of therapeutic agents for OCC, such as immunotherapies as well as molecular targeted drugs (46).

\section{Acknowledgements}

The present study was supported in part by a Grant-in-Aid for Scientific Research (B) and Grant-in-Aid for Scientific Research on Innovative Areas from The Japan Society for the Promotion of Science (JSPS KAKENHI grant no.JP: 15H04761 and 16H06277). Y.D. is a member of the Shiga Cancer Treatment Project supported by Shiga Prefecture (Japan).

\section{References}

1. Siegel R, Ma J, Zou Z and Jemal A: Cancer statistics, 2014. CA Cancer J Clin 64: 9-29, 2014

2. Chen PC, Kuo C, Pan CC and Chou MY: Risk of oral cancer associated with human papillomavirus infection, betel quid chewing, and cigarette smoking in Taiwan - an integrated molecular and epidemiological study of 58 cases. J Oral Pathol Med 31: 317-322, 2002.

3. Franceschi S, Talamini R, Barra S, Barón AE, Negri E, Bidoli E, Serraino D and La Vecchia C: Smoking and drinking in relation to cancers of the oral cavity, pharynx, larynx, and esophagus in northern Italy. Cancer Res 50: 6502-6507, 1990.

4. Cancela MC, Ramadas K, Fayette JM, Thomas G, Muwonge R, Chapuis F, Thara S, Sankaranarayanan R and Sauvaget C: Alcohol intake and oral cavity cancer risk among men in a prospective study in Kerala, India. Community Dent Oral Epidemiol 37: 342-349, 2009.

5. Kimple RJ, Smith MA, Blitzer GC, Torres AD, Martin JA, Yang RZ, Peet CR, Lorenz LD, Nickel KP, Klingelhutz AJ, et al: Enhanced radiation sensitivity in HPV-positive head and neck cancer. Cancer Res 73: 4791-4800, 2013.

6. Chinn SB and Myers JN: Oral cavity carcinoma: Current management, controversies, and future directions. J Clin Oncol 33: 3269-3276, 2015.

7. da Silva SD, Hier M, Mlynarek A, Kowalski LP and AlaouiJamali MA: Recurrent oral cancer: Current and emerging therapeutic approaches. Front Pharmacol 3: 149, 2012.

8. Poh CF, Durham JS, Brasher PM, Anderson DW, Berean KW, MacAulay CE, Lee JJ and Rosin MP: Canadian Opticallyguided approach for Oral Lesions Surgical (COOLS) trial: Study protocol for a randomized controlled trial. BMC Cancer 11: 462, 2011.

9. Carvalho AL, Kowalski LP, Agra IM, Pontes E, Campos OD and Pellizzon AC: Treatment results on advanced neck metastasis (N3) from head and neck squamous carcinoma. Otolaryngol Head Neck Surg 132: 862-868, 2005.

10. Furness S, Glenny AM, Worthington HV, Pavitt S, Oliver R, Clarkson JE, Macluskey M, Chan KK and Conway DI: Interventions for the treatment of oral cavity and oropharyngeal cancer: Chemotherapy. Cochrane Database Syst Rev (4): CD006386, 2011.
11. National Cancer Institute: Surveillance, Epidemiology, and End Results (SEER) Program, National Cancer Institute Surveillance Research Program, based on November 2006 submission of SEER series 9 (1996-2003), 2006.

12. Chinn SB, Spector ME, Bellile EL, McHugh JB, Gernon TJ, Bradford CR, Wolf GT, Eisbruch A and Chepeha DB: Impact of perineural invasion in the pathologically NO neck in oral cavity squamous cell carcinoma. Otolaryngol Head Neck Surg 149: 893-899, 2013.

13. Daigo Y and Nakamura Y: From cancer genomics to thoracic oncology: Discovery of new biomarkers and therapeutic targets for lung and esophageal carcinoma. Gen Thorac Cardiovasc Surg 56: 43-53, 2008.

14. Daigo Y, Takano A, Teramoto K, Chung S and Nakamura Y: A systematic approach to the development of novel therapeutics for lung cancer using genomic analyses. Clin Pharmacol Ther 94: 218-223, 2013.

15. Ishikawa N, Daigo Y, Takano A, Taniwaki M, Kato T, Hayama S, Murakami H, Takeshima Y, Inai K, Nishimura H, et al: Increases of amphiregulin and transforming growth factor-alpha in serum as predictors of poor response to gefitinib among patients with advanced non-small cell lung cancers. Cancer Res 65: 9176-9184, 2005.

16. Ishikawa N, Daigo Y, Yasui W, Inai K, Nishimura H, Tsuchiya E, Kohno N and Nakamura Y: ADAM8 as a novel serological and histochemical marker for lung cancer. Clin Cancer Res 10: 8363-8370, 2004.

17. Kakiuchi S, Daigo Y, Ishikawa N, Furukawa C, Tsunoda $\mathrm{T}$, Yano S, Nakagawa K, Tsuruo T, Kohno N, Fukuoka M, et al: Prediction of sensitivity of advanced non-small cell lung cancers to gefitinib (Iressa, ZD1839). Hum Mol Genet 13: 3029-3043, 2004.

18. Kato T, Daigo Y, Hayama S, Ishikawa N, Yamabuki T, Ito T, Miyamoto M, Kondo S and Nakamura Y: A novel human tRNAdihydrouridine synthase involved in pulmonary carcinogenesis. Cancer Res 65: 5638-5646, 2005.

19. Kikuchi T, Daigo Y, Katagiri T, Tsunoda T, Okada K, Kakiuchi S, Zembutsu H, Furukawa Y, Kawamura M, Kobayashi K, et al: Expression profiles of non-small cell lung cancers on cDNA microarrays: Identification of genes for prediction of lymph-node metastasis and sensitivity to anti-cancer drugs. Oncogene 22: 2192-2205, 2003.

20. Suzuki C, Daigo Y, Ishikawa N, Kato T, Hayama S, Ito T, Tsuchiya E and Nakamura Y: ANLN plays a critical role in human lung carcinogenesis through the activation of RHOA and by involvement in the phosphoinositide 3-kinase/AKT pathway. Cancer Res 65: 11314-11325, 2005.

21. Kakiuchi S, Daigo Y, Tsunoda T, Yano S, Sone S and Nakamura Y: Genome-wide analysis of organ-preferential metastasis of human small cell lung cancer in mice. Mol Cancer Res 1: 485-499, 2003.

22. Taniwaki M, Daigo Y, Ishikawa N, Takano A, Tsunoda T, Yasui W, Inai K, Kohno N and Nakamura Y: Gene expression profiles of small-cell lung cancers: Molecular signatures of lung cancer. Int J Oncol 29: 567-575, 2006.

23. Oshita H, Nishino R, Takano A, Fujitomo T, Aragaki M, Kato T, Akiyama H, Tsuchiya E, Kohno N, Nakamura Y, et al: RASEF is a novel diagnostic biomarker and a therapeutic target for lung cancer. Mol Cancer Res 11: 937-951, 2013.

24. Hayama S, Daigo Y, Yamabuki T, Hirata D, Kato T, Miyamoto M, Ito T, Tsuchiya E, Kondo S and Nakamura Y: Phosphorylation and activation of cell division cycle associated 8 by aurora kinase B plays a significant role in human lung carcinogenesis. Cancer Res 67: 4113-4122, 2007.

25. Ishikawa N, Daigo Y, Takano A, Taniwaki M, Kato T, Tanaka S, Yasui W, Takeshima Y, Inai K, Nishimura H, et al: Characterization of SEZ6L2 cell-surface protein as a novel prognostic marker for lung cancer. Cancer Sci 97: 737-745, 2006.

26. Kato T, Sato N, Hayama S, Yamabuki T, Ito T, Miyamoto M, Kondo S, Nakamura Y and Daigo Y: Activation of Holliday junction recognizing protein involved in the chromosomal stability and immortality of cancer cells. Cancer Res 67: 8544-8553, 2007.

27. Suzuki C, Takahashi K, Hayama S, Ishikawa N, Kato T, Ito T, Tsuchiya E, Nakamura Y and Daigo Y: Identification of Myc-associated protein with JmjC domain as a novel therapeutic target oncogene for lung cancer. Mol Cancer Ther 6: 542-551, 2007. 
28. Takahashi K, Furukawa C, Takano A, Ishikawa N, Kato T, Hayama S, Suzuki C, Yasui W, Inai K, Sone S, et al: The neuromedin U-growth hormone secretagogue receptor $1 \mathrm{~b} /$ neurotensin receptor 1 oncogenic signaling pathway as a therapeutic target for lung cancer. Cancer Res 66: 9408-9419, 2006.

29. Taniwaki M, Takano A, Ishikawa N, Yasui W, Inai $K$, Nishimura H, Tsuchiya E, Kohno N, Nakamura Y and Daigo Y: Activation of KIF4A as a prognostic biomarker and therapeutic target for lung cancer. Clin Cancer Res 13: 6624-6631, 2007.

30. Yamabuki T, Takano A, Hayama S, Ishikawa N, Kato T, Miyamoto M, Ito T, Ito $\mathrm{H}$, Miyagi Y, Nakayama $\mathrm{H}$, et al: Dikkopf-1 as a novel serologic and prognostic biomarker for lung and esophageal carcinomas. Cancer Res 67: 2517-2525, 2007.

31. Fujitomo T, Daigo Y, Matsuda K, Ueda K and Nakamura Y: Identification of a nuclear protein, LRRC42, involved in lung carcinogenesis. Int J Oncol 45: 147-156, 2014.

32. Nguyen MH, Koinuma J, Ueda K, Ito T, Tsuchiya E, Nakamura Y and Daigo Y: Phosphorylation and activation of cell division cycle associated 5 by mitogen-activated protein kinase play a crucial role in human lung carcinogenesis. Cancer Res 70: 5337-5347, 2010.

33. Hayama S, Daigo $\mathrm{Y}$, Kato $\mathrm{T}$, Ishikawa N, Yamabuki $\mathrm{T}$, Miyamoto M, Ito T, Tsuchiya E, Kondo S and Nakamura Y: Activation of CDCA1-KNTC2, members of centromere protein complex, involved in pulmonary carcinogenesis. Cancer Res 66: 10339-10348, 2006

34. Tomita Y, Yuno A, Tsukamoto H, Senju S, Yoshimura S, Osawa R, Kuroda Y, Hirayama M, Irie A, Hamada A, et al: Identification of CDCA1-derived long peptides bearing both $\mathrm{CD}^{+}$and $\mathrm{CD} 8^{+}$ T-cell epitopes: CDCA1-specific $\mathrm{CD}^{+} \mathrm{T}$-cell immunity in cancer patients. Int J Cancer 134: 352-366, 2014.

35. Kobayashi Y, Takano A, Miyagi Y, Tsuchiya E, Sonoda $\mathrm{H}$ Shimizu T, Okabe H, Tani T, Fujiyama Y and Daigo Y: Cell division cycle-associated protein 1 overexpression is essential for the malignant potential of colorectal cancers. Int J Oncol 44: 69-77, 2014.

36. Harao M, Hirata S, Irie A, Senju S, Nakatsura T, Komori H, Ikuta Y, Yokomine K, Imai K, Inoue M, et al: HLA-A2-restricted CTL epitopes of a novel lung cancer-associated cancer testis antigen, cell division cycle associated 1 , can induce tumorreactive CTL. Int J Cancer 123: 2616-2625, 2008.

37. Ciferri C, De Luca J, Monzani S, Ferrari KJ, Ristic D, Wyman C, Stark H, Kilmartin J, Salmon ED and Musacchio A: Architecture of the human ndc80-hecl complex, a critical constituent of the outer kinetochore. J Biol Chem 280: 29088-29095, 2005.
38. Kaneko N, Miura K, Gu Z, Karasawa H, Ohnuma S, Sasaki H, Tsukamoto N, Yokoyama S, Yamamura A, Nagase $\mathrm{H}$, et al: siRNA-mediated knockdown against CDCA1 and KNTC2, both frequently overexpressed in colorectal and gastric cancers, suppresses cell proliferation and induces apoptosis. Biochem Biophys Res Commun 390: 1235-1240, 2009.

39. van Duin M, Broyl A, de Knegt Y, Goldschmidt H, Richardson PG, Hop WC, van der Holt B, Joseph-Pietras D, Mulligan G, Neuwirth R, et al: Cancer testis antigens in newly diagnosed and relapse multiple myeloma: Prognostic markers and potential targets for immunotherapy. Haematologica 96: 1662-1669, 2011.

40. Wan X, O'Quinn RP, Pierce HL, Joglekar AP, Gall WE, DeLuca JG, Carroll CW, Liu ST, Yen TJ, McEwen BF, et al: Protein architecture of the human kinetochore microtubule attachment site. Cell 137: 672-684, 2009.

41. Sundin LJ, Guimaraes GJ and Deluca JG: The NDC80 complex proteins Nuf2 and Hec1 make distinct contributions to kinetochore-microtubule attachment in mitosis. Mol Biol Cell 22: 759-768, 2011.

42. DeLuca JG, Howell BJ, Canman JC, Hickey JM, Fang G and Salmon ED: Nuf2 and $\mathrm{Hecl}$ are required for retention of the checkpoint proteins Mad1 and Mad2 to kinetochores. Curr Biol 13: 2103-2109, 2003

43. DeLuca JG, Moree B, Hickey JM, Kilmartin JV and Salmon ED: hNuf2 inhibition blocks stable kinetochore-microtubule attachment and induces mitotic cell death in HeLa cells. J Cell Biol 159: 549-555, 2002.

44. Liu D, Ding X, Du J, Cai X, Huang Y, Ward T, Shaw A, Yang Y, Hu R, Jin C, et al: Human NUF2 interacts with centromere-associated protein $\mathrm{E}$ and is essential for a stable spindle microtubule-kinetochore attachment. J Biol Chem 282: 21415-21424, 2007.

45. Zhai Y, Kronebusch PJ and Borisy GG: Kinetochore microtubule dynamics and the metaphase-anaphase transition. J Cell Biol 131: 721-734, 1995.

46. Yoshitake Y, Fukuma D, Yuno A, Hirayama M, Nakayama $H$, Tanaka T, Nagata M, Takamune Y, Kawahara K, Nakagawa Y, et al: Phase II clinical trial of multiple peptide vaccination for advanced head and neck cancer patients revealed induction of immune responses and improved OS. Clin Cancer Res 21: 312-321, 2015. 